\title{
Pengaruh Interval Training Terhadap V02 Max Atlet Bola Basket IKIP PGRI Pontianak
}

\author{
1Mohammad Sabransyah, ${ }^{2}$ Asmutiar, ${ }^{3}$ Rovi Pahliwandari \\ 1,2,3IKIP PGRI Pontianak, Pontianak, Kalimantan Barat, Indonesia \\ 1sabran.pjkr@gmail.com, 2asmu_tiar@yahoo.com, 3rovipahliwandari@gmail.com
}

\begin{abstract}
ABSTRAK
Penelitian ini bertujuan untuk mengetahui pengaruh Inerval Training terhadap VO2Max atlet Bola basket di IKIP PGRI Pontianak. Metode penelitian menggunkan metode eksperimen. Populasi yang digunakan dalam penelitian ini adalah seluruh anggota tim Bola Basket IKIP PGRI Pontianak yang berjumlah 18 Orang. Teknik sampling pada penelitian ini menggunakan total sampling, maka untuk sampel penelitian ini adalah seluruh populasi, yaitu seluruh anggota tim Bola Basket IKIP PGRI Pontianak yang berjumlah 18 Orang. Instrumen yang digunakan untuk pengambilan data penelitian adalah dengan menggunakan Bleep test. Hasil penelitian menunjukan bahwa ada pengaruh latihan Interval Training terhadap Vo2max atlet Bola basket IKIP PGRI Pontianak. Saran untuk para pelatih agar dapat menerapkan proses latihan yang tidak keluar dari prinsip-prinsip latihan, dan bagi para peneliti selanjutnya diharapkan untuk meneliti dengan program latihan yang lain.
\end{abstract}

Kata Kunci: Interval Training, VO2Max, Bola Basket

\section{ABSTRAC}

The game of basketball and volleyball has a pattern of motion and use of almost the same body parts from both techniques. But it is not yet known which shoulder strength and leg strength of the two sports branches have high strength to do the jumping, smass and shooting techniques. This research is to find out whether or not there is a comparison of the shoulder and limb strength of basketball and volleyball players. Causal Comparative (causal comparative research). Push and pull test results for basketball and volleyball players, the calculated $t$ value is $\mathbf{- 0 . 1 8 7}$ round the value and compare it with the table. $T$ value (0.187) < table $0.05 ; 14=1.76131$ so that Ho is accepted. Back and Leg Dynamometer test results for basketball and volleyball players, the calculated $t$ value is 0.604 round that value and compare it to the table. $T$ value $(0.604)<$ t table $0.05 ; 14=1.76131$ so that Ho is accepted. Thus the hypothesis which states whether there is a comparison between shoulder strength and leg strength of basketball players and volleyball players of IKIP PGRI Pontianak students, is not accepted.

Keyword: Basketball, Volleyball, Shoulder Strength and Leg Strength Alamat Korespondensi: IKIP PGRI Pontianak Email: sabran.pjkr@gmail.com 


\section{PENDAHULUAN}

Dalam permainan bola basket seorang pemain harus dapat bergerak cepat dan memiliki daya tahan kardiorespirasi yang baik. Hal ini dikarenakan para pemain bola basket harus dapat melakukan penyerangan dan bertahan dalam waktu yang singkat dan terus menerus selama pertandingan yang kurang lebih 4x10 menit dengan ukuran lapangan yang relatif kecil antara panjang 26-28 meter dan lebar 14-15 meter. Salah satu komponen kebugaran yang harus dimiliki pemain bol basket adalah daya tahan jantung dan paru-paru (Mc Gee, 2007). Pada dasarnya, ada dua macam daya tahan jantung dan paru-paru, yaitu aerobik dan anaerobik. Pada saat permainan bola basket daya tahan anaerobik dilakukan untuk gerkan-gerakan eksplosif yang membutuhkan ledakan otot, tetapi secara umum, pola gerakan, serta waktu pemulihan, daya tahan aerobik memiliki kontribusi yang lebih besar (Oliver, 2009).

Bola basket merupakan salah satu cabang olahraga beregu yang mengalami perkembangan yang cukup pesat. Hal ini disebabkan karena jenis olahraga ini bukan hanya sebagai olahraga prestasi tetapi juga sebagai olahraga pendidikan ataupun olahraga rekreasi (Kosasih, 2008). Maka dari itu, untuk melakukan olahraga ini seorang pemain harus memiliki unsur atau komponen fisik yang baik, seperti kekuatan, daya tahan, kecepatan kelentukan, kelincahan, stamina dan koordinasi (Harsono, 2011). Dalam mendukung aktivitas fisiknya, seorang pemain bola basket harus meningkatkan asupan oksigen dalam darahnya sebagai suplai energi bagi tubuhnya. Asupan oksigen atlet bola basket harus maximal agar bisa menunjang kebutuhan selama berolahraga yang berakibat pada level kebugarannya. Volume oksigen Maksimal atau yang disingkat VO2Max adalah jumlah maksimal oksigen yang dapat di konsumsi selama aktivitas fisik yang intens sampai akhirnya terjadi kelelahan (Rahmat, 2016).

Nilai VO2Max ini bergantung pada keadaan kardiovaskular, respirasi, hematologi, dan kemampuan oksidatif otot (Junusal, 2010). Pengukuran nilai VO2Max ini rupanya dapat digunakan untuk menganalisis efek dari suatu program latihan fisik. Pada anak yang sedang mengalami perkembangan, latihan fisik dapat memberikan mafaat yang dapat baik untuk kesehatan. Agar efektif, latihan fisik sebainya bersifat endurance (ketahanan) dan meliputi durasi, frekuensi, dan intensitas tertentun (Harsono, 2011). Dan salah satu bentuk latihan fisik yang dapat dilakukan untuk meningkatkan daya tahan kardiorespirasi adalah dengan interval training.

Interval training adalah latihan kecepatan berupa lari yang jaraknya telah ditentukan (4060 meter) sedemikian rupa sehingga meningkatkan daya tahan dan kecepatan (Indrayana, 2012). Penerapan bentuk latihan ini memang cocok dilakukan pada cabang olahraga yang memiliki intensitas dan kompleksitas permainan yang tinggi, karena pada jenis permainan tersebut dibutuhkan daya tahan atau staminan seorang pemain yang baik (Syaifudin, 2015). Pada kesempatan kali ini, peneliti ingin mencoba menerapkan bentuk latihan interval ini kepada para atlet bola basket IKIP PGRI Pontianak, yang dimana tujuannya diharapkan disamping nantinya 
dapat mengetahui secara pasti tingkat VO2Max para pemainnya, juga sebagai bahan evaluasi atas program latihan yang telah dijalankan atau sebagai bahan rujukan dalam membuat perencanaan, rancangan program latihan yang akan diterapkan.

Berdasarkan pemaparan tersebut, mengenai bentuk latihn interval dan pentingnya daya tahan kardiorespirasi bagi para pemain atau atlet basket, kiranya peneliti tertarik untuk mengambil penelitian tentang pengaruh interval training terhadap VO2Max atlet bola basket di IKIP PGRI Pontianak, sehingga tujuan dari penelitian ini adalah untuk mengetahui apakah latihan interval dapat mempengaruhi VO2Max.

\section{METODE}

Metode yang digunakan pada penelitian ini adalah metode eksperimen, dengan menggunakan desain one group pretest postest. Dimana metode eksperimen digunakan untuk mencari sebab akibat ataupun pengaruh dari suatu variabel dengan variabel lainnya (Sugiyono, 2017). Untuk desain penelitiannya dapat dilihat sebagai berikut:

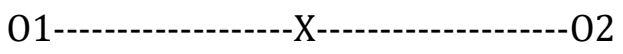

Gambar 1. Desain Penelitian

Keterangan:

$01 \quad$ : Tes Awal

$\mathrm{X} \quad$ : Treatment (Interval Training)

02 : Tes Akhir

Populasi yang digunakan pada penelitian ini adalah anggota tim bola basket IKIP PGRI Pontianak yang berjumlah 18 orang. Dimana sampel yang digunakan adalah seluruh populasi, karena teknik sampling yang digunakan menggunakan teknik total sampling. Jadi jumlah sampel yang digunakan dalam penelitian ini adalah sebanyak 18 orang terdiri dari para pemain atau atlet bola basket yang tergabung pada tim bola basket IKIP PGRI Pontianak.

Sesuai dengan permasalahan yang akan diujikan, yaitu VO2Max pemain bola basket, maka instrumen atau alat ukur penelitian yang digunakan adalah beep test. Beeep test digunakan untuk mengambil data daya tahan atlet sehingga Vo2Max dapat terlihat datanya, yaitu merupakan suatu kegiatan untuk mengukur VO2Max, dimana para peserta melakukan lari bolak - balik dengan jarak 20 m, yang dimulai dengan lari mengikuti irama music "beep" dimulai dari pelan-pelan secara bertahap yang semakin lama semakin cepat hingga atlet tidak mampu mengikuti irama waktu lari (Nurhasan \& Cholil, 2013). Untuk lebih jelasnya dapat dilihat pada gambar berikut ini: 


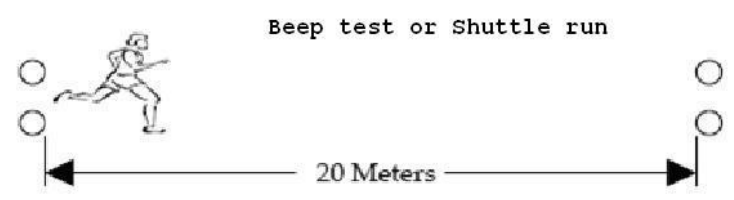

Gambar 2. Beep Test

Teknik analisis data pada penelitian ini menggunakan pendekatan kuantitatif dengan pengujian statistika yang dimana prosedurnya pertama menghitung rata-rata dan simpangan baku pada setiap periode tes, melakukan pengujian persyaratan analisis yaitu uji normalitas dan uji homogenitas, dan selanjutnya pengujian hipotesis dengan uji - $t$ dengan uji beda.

\section{HASIL DAN PEMBAHASAN}

\section{Deskripsi Hasil Tes}

Uraian deskripsi data hasil penelitian ini bertujuan untuk melihat secara umum gambaran hasil skor dari masing-masing periode tes adalah sebagai berikut:

Tabel 1. Deskripsi Hasil Tes Awal (Beep Test)

\begin{tabular}{|c|c|c|c|}
\hline No. & Rentang Skor & Kategori & Frekuensi \\
\hline 1 & $>55,9$ & Luar Biasa & 0 \\
\hline 2 & $51-55,9$ & Sangat Baik & 0 \\
\hline 3 & $45,2-50,9$ & Baik & 1 \\
\hline 4 & $38,4-45,1$ & Rata-Rata & 8 \\
\hline 5 & $35,0-38,3$ & Kurang & 5 \\
\hline 6 & $<35,0$ & Sangat Kurang & 4 \\
\hline \multicolumn{3}{|c|}{ Jumlah } & 18 \\
\hline
\end{tabular}

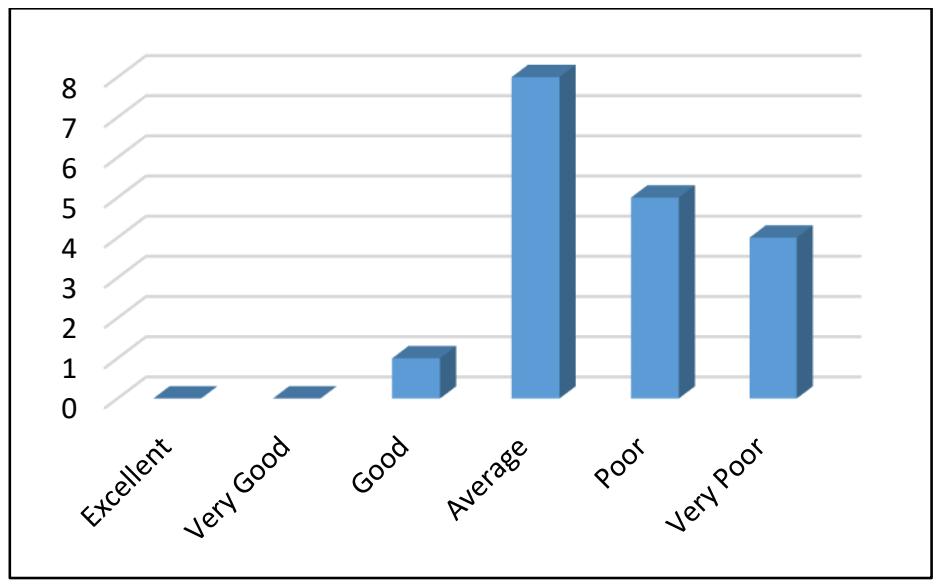

Gambar 3. Diagram Hasil Tes Awal 
Tabel 2. Deskripsi Hasil Tes Awal (Beep Test)

\begin{tabular}{|c|c|c|c|}
\hline No. & Rentang Skor & Kategori & Frekuensi \\
\hline 1 & $>55,9$ & Luar Biasa & 0 \\
\hline 2 & $51-55,9$ & Sangat Baik & 4 \\
\hline 3 & $45,2-50,9$ & Baik & 10 \\
\hline 4 & $38,4-45,1$ & Rata-Rata & 4 \\
\hline 5 & $35,0-38,3$ & Kurang & 0 \\
\hline 6 & $<35,0$ & Sangat Kurang & 0 \\
\hline \multicolumn{3}{|c|}{ Jumlah } & 18 \\
\hline
\end{tabular}

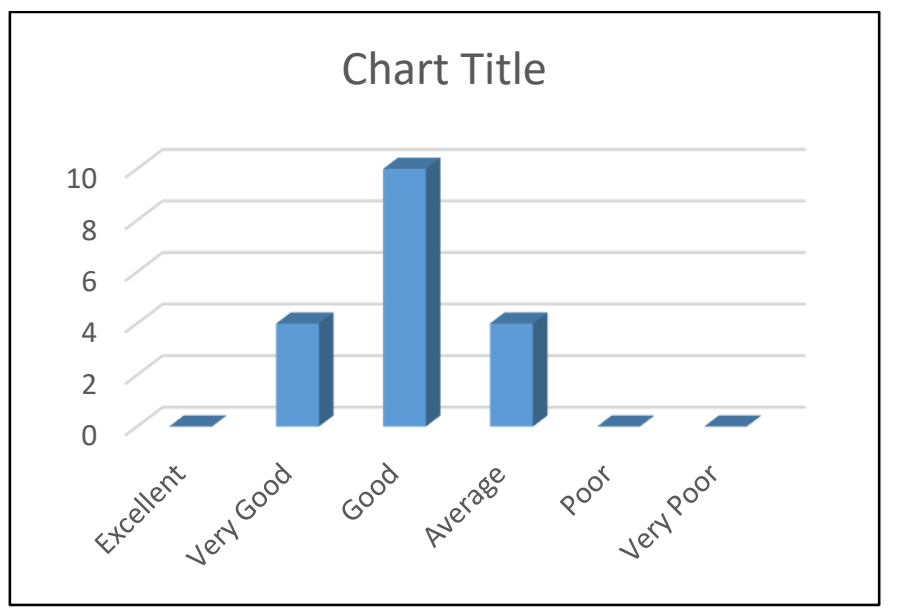

Gambar 4. Diagram Hasil Tes Akhir

Berdasarkan pada data table dan diagram tes awal dan tes akhir secara visualisasi dapat kita lihat adanya perbedaan, dimana pada tes awal terlihat masih terdapat pemain yang memiliki VO2Max yang berada di level sangat kurang dan kurang, sedangkan pada tes akhir atau setelah diberi perlakuan berupa latihan interval terlihat sudah tidak ada lagi pemain yang berada di level sangat kurang maupun kurang.

Hal ini dapat dibuktikan dengan perolehan nilai rata-rata dan simpangan baku dari masing-masing periode tes tersebut yang penulis tuliskan pada table 3 berikut ini:

Tabel 3. Hasil Rata-Rata dan Simpangan Baku (Beep Test)

\begin{tabular}{|c|c|c|}
\hline Periode Tes & Rata-Rata & Simpangan Baku \\
\hline Tes Awal & 37,31 & 5,69 \\
\hline Tes Akhir & 46,92 & 4,10 \\
\hline
\end{tabular}

Dari hasil table tersebut, dapat dilihat bahwa nilai rata-rata pada tes awal mendapat skor 37,31 dengan simpangan baku 5,69, sedangkan nilai rata-rata pada tes akhir mendapat skor 46,92 dengan simpangan baku sebesar 4,10. Setelah menghitung nilai rata-rata dan simpangan 
baku pada setiap periode tes, maka selanjutnya adalah melakukan pengujian persyaratan analisis yang akan penulis paparkan pada bagian selanjutnya.

\section{Pengujian Persyaratan Analisis}

\section{a. Uji Normalitas}

Uji normalitas dimaksudkan untuk mengetahui apakah variable-variabel dalam penelitian mempunyai sebaran distribusi normal atau tidak. Penghitungan uji normalitas ini menggunakan rumus Kolmogorov Smirnov, dengan pengolahan menggunakan bantuan program SPSS 20. Berikut hasil pengujiannya dapat dilihat pada tabel 4 di bawah ini:

Tabel 4. Hasil Uji Normalitas

\begin{tabular}{|c|c|c|c|}
\hline Periode Tes & Asymp.Sig & Sig. & Kesimpulan \\
\hline Tes Awal & 0.213 & \multirow{2}{*}{0.05} & Normal \\
\cline { 1 - 2 } Tes Akhir & 0.268 & & Normal \\
\hline
\end{tabular}

Dari tabel di atas dapat diketahui bahwa nilai Asymp.Sig dari masing-masing periode tes yaitu 0,213 pada tes awal dan 0,268 pada tes akhir lebih besar dari 0,05. Maka dari itu, dapat disimpulkan bahwa kedua data tersebut berdistribusi normal.

\section{b. Uji Homogenitas}

Setelah melakukan pengujian normalitas, selanjutnya melakukan pengujian homogenitas menggunakan pendekatan leaven's test pada program SPSS 20, dan di dapat data sebagai berikut:

Tabel 5. Hasil Uji Normalitas

\begin{tabular}{|c|c|c|c|}
\hline $\begin{array}{c}\text { Kelompok } \\
\text { Tes }\end{array}$ & Leaven's Test & Sig. & Kesimpulan \\
\hline $\begin{array}{c}\text { Tes Awal } \\
\text { Tes Akhir }\end{array}$ & 0.195 & 0.05 & Homogen \\
\hline
\end{tabular}

Berdasarkan tabel di atas dapat diketahui bahwa nilai leaven's test dari kedua kelompok tersebut adalah 0,195 lebih besar dari 0,05. Maka dari itu, dapat disimpulkan bahwa data memiliki varians yang sama atau populasinya homogen.

\section{Pengujian Hipotesis}

Tahap selanjutnya adalah melakukan pengujian hipotesis dengan menggunakan pendekatan statistika uji-t beda. Hasilnya dapat dilihat pada tabel 6 berikut ini:

Tabel 6. Hasil Pengujian Hipotesis

\begin{tabular}{|c|c|c|c|c|c|c|}
\hline Tes & $\mathbf{X}$ & $\mathbf{X}$ (Beda) & S (Beda) & T hitung & T tabel (0,975:17) & Kesimpulan \\
\hline Tes Awal & 37,31 & \multirow{2}{*}{9,61} & 4,72 & 6,87 & 2,11 & Signifikan \\
\hline Tes Akhir & 46,92 & & & & & \\
\hline
\end{tabular}


Berdasarkan pada tabel di atas, dapat diketahui bahwa nilai t hitung 6,87 $>2,11$ pada $t$ tabel dimana pada taraf signifikansi $0,975 \mathrm{dk}=17$. Dengan begitu dapat disimpulkan bahwa latihan interval memiliki pengaruh yang signifikan terhadap VO2Max atlet bola basket. Latihan interval terbukti memiliki peranan besar dalam meningkatkan VO2Max seseorang, tapi dengan ketentuan latihan yang diberikan harus sesuai dengan prinsip-prinsip latihan, dengan juga memperhatikan karakteristik dari para atletnya.

Proses peningkatan kemampuan VO2Max secara khusus hanya dapat ditingkatkan dengan latihan yang baik. Proses latihan dengan peningkatan beban latihan dari setiap sesi latihan akan membantu seseorang untuk meningkatkan kemampuannya secara maksimal. Akan tetapi, sebaliknya apabila proses latihan yang diberikan tidak melaksanakan prinsip latihan yang baik maka hasil latihan juga akan kurang memuaskan (Syaifudin, 2015). Pemilihan metode latihan yang tepat dengan dosis yang sesuai akan memberikan dampak efektif terhadap hasil yang ingin dicapai. Seperti halnya latihan interval training efektif digunakan untuk meningkatkan VO2Max. Bentuk latihan yang sesuai dengan prinsip-prinsip latihan serta takaran yang ada diharapkan dapat memberikan hasil yang maksimal, sehingga tujuan dari program tersebut tercapai (Suharjana, 2013).

\section{KESIMPULAN}

Dari hasil penelitian yang telah dilakukan dengan proses pengolahan dan analisis data, maka dalam hal ini penulis menyimpulkan bahwa interval training memberikan pengaruh yang signifikan terhadap VO2Max para pemain bola basket IKIP PGRI Pontianak. Maka dari itu, penulis juga memberikan beberapa masukan khususnya kepada para pelatih bola basket, bahwa dengan latihan interval dapat meningkatkan daya tahan para atlet, namun kiranya tipe-tipe latihan harus lebih variatif guna mencegah kejenuhan bagi atlet, serta kepada para peneliti selanjutnya yang ingin meneliti pada topik yang sama, alahkah lebih baiknya dapat melakukannya dengan tipe-tipe latihan interval yang berbeda sehingga lebih spesifik pada setiap cabang olahraga.

\section{DAFTAR PUSTAKA}

Hairy, Junusal. (2010). Dasar-Dasar Kesehatan Olahraga. Jakarta; Departemen Pendidikan Nasional.

Harsono, M. S., \& Drs, M. S. (2011). Coaching dan Aspek-aspek Psikologis dalam Coaching. Direktorat Jendral Pendidikan Tinggi: Jakarta

Harsuki. (2003). Perkembangan Olahraga Terkini. Jakarta: Rajawali Sport, Rajagrafindo Persada

Indrayana, B. (2012). Perbedaan Pengaruh Latihan Interval Training Dan Fartlek Terhadap Daya Tahan Kordiovaskuler Pada Atlet Junior Putra Teakwondo Wild Club Medan, Cerdas Sifa, Vol.1, Edisi No.1. Mei - Agustus 
Junusal, H. 2010. Dasar-Dasar Kesehatan Olahraga. Jakarta: Departemen Pendidikan Nasional.

Kosasih, Dann. (2008). Fundamental Basketball. Semarang: Karangturi Media

McGee, Kathy. (2007). Coaching Basketball Technical And Tactical Skills. USA: Human Kinetics.

Nurhasan \& Cholil. (2011). Tes dan Pengukuran Keolahragaan. Bandung: STKIP Pasundan

Oliver, Jon. (2009). Dasar-Dasar Bola Basket. Bandung: Pakar Raya

Rahmat, A H. 2016. Pengaruh Penerapan Daya Tahan Kardiovaskuler (Vo2max) Dalam Permainan Sepakbola Ps Bina Utama, Jurnal Curricula Kopertis Wil X 1, Vol 1, No 2

Syaifudin, W A. (2015). “Pengaruh Interval Training Terhadap Kebugaran Jasmani dan VO2max Siswa Kelas IX SMP Negeri 3 Negeri Katon. 